\title{
Arteria Lusoria: An Uncommon Cause of Dysphagia
}

\section{Artéria Lusória: Uma Causa Incomum de Disfagia}

Sofia AMANTE $\rrbracket^{1}$, Rafaela SOUSA ${ }^{1}$, Rui AMARAL ${ }^{1}$

Acta Med Port 2020 Jan;33(1):65-65 - https://doi.org/10.20344/amp.11641

Keywords: Deglutition Disorders; Subclavian Artery/abnormalities

Palavras-chave: Artéria Subclávia/anomalias congénitas; Perturbações da Deglutição

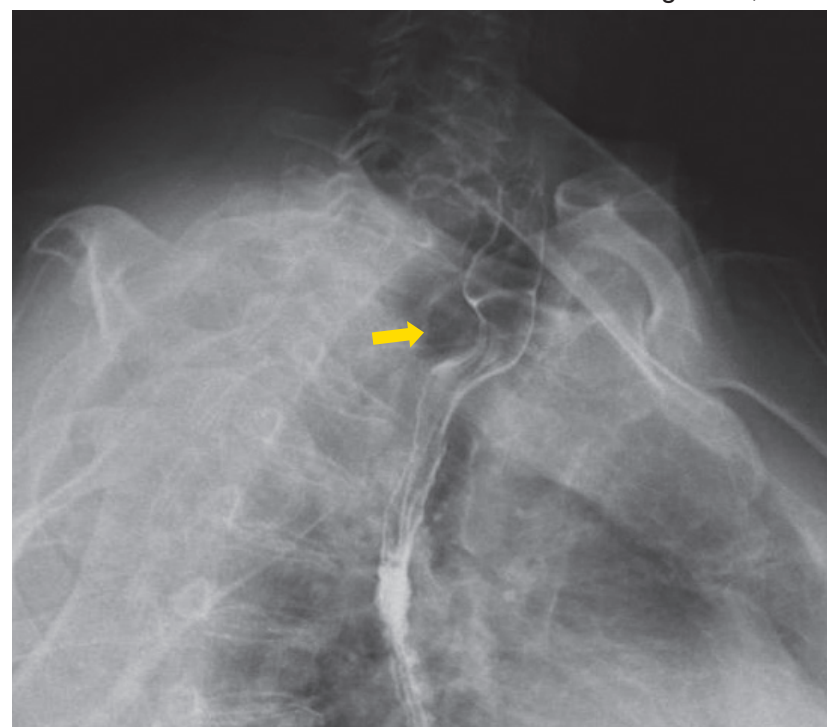

Figure 1 - Right anterior oblique view of a barium esophagram showing a posterior and extrinsic indentation of the middle esophagus (arrow)

A 71-year-old female presented with a two-year history of intermittent dysphagia for solids and a $6 \mathrm{~kg}$ weight loss. An esophagram was performed, revealing an extrinsic indentation with anterior displacement of the esophagus (Fig. 1). Subsequent computed tomography angiography showed an aberrant right subclavian artery (ARSA) with a retro-esophageal course, slightly compressing the esophagus, as the probable cause of symptoms (Fig. 2).

Dysphagia lusoria is a swallowing impairment due to vascular compression of the esophagus. ${ }^{1-4}$ Typically, the causative vessel is a retro-esophageal ARSA, originating

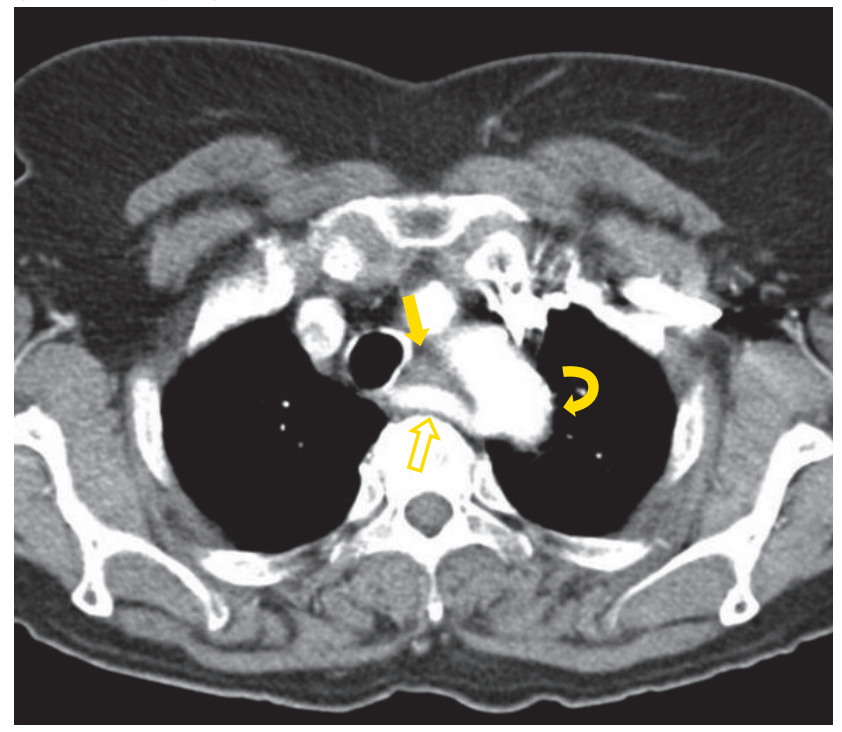

Figure 2 - Computed tomography angiography (axial view) showing an aberrant right subclavian artery (hollow arrow), arising distally from the aortic arch (curved arrow), slightly compressing the posterior wall of the esophagus (yellow arrow)

from the left-sided aortic arch, with a reported incidence of $0.5 \%-2 \%$, of which only $20 \%-40 \%$ develop symptoms. ${ }^{1,4,5}$ Children generally present with respiratory symptoms, owing to a more flexible trachea, while adults develop dysphagia, because of age-related decreased vascular compliance. $^{3}$

Mild symptoms only require dietary modifications, including eating slower and chewing properly. Severe cases may warrant surgical treatment. ${ }^{4}$

Our patient agreed with conservative treatment, showing progressive clinical improvement.

PROTECTION OF HUMANS AND ANIMALS: The authors declare that the procedures were followed according to the regulations established by the Clinical Research and Ethics Committee and to the Helsinki Declaration of the World Medical Association.

DATA CONFIDENTIALITY: The authors declare having followed the protocols in use at their working center regarding patients' data publication.

INFORMED CONSENT: Obtained.

CONFLICTS OF INTEREST: All authors report no conflict of interest.

FUNDING SOURCES: The authors declare that there were no external sources of study for the performance of this article.

\section{REFERENCES}

1. Blanquicett C, Dunn T, Nanda A, Weber F. An uncommon cause of dysphagia in a 35 year old male. Pract Gastroenterol. 2017;41:40-2.

2. Leite TF, Pires LA, Cisne R, Babinski MA, Chagas CA. Clinical discussion of the arteria lusoria: a case report. J Vasc Bras. $2017 ; 16: 339-42$.

3. Silva HM, Silva G, Lima R. Dysphaga lusoria: uncommon cause of dysphagia in children. Rev Esp Enferm Dig. 2018;110:600.

4. Bennett AL, Cock C, Heddle R, Morcom RK. Dysphagia lusoria: a late onset presentation. World J Gastroenterol. 2013;19:2433-6.

5. Ka-Tak W, Lam WW, Yu SC. MD. CT of an aberrant right subclavian artery and of bilateral vertebral arteries with anomalous origins. AJR Am J Roentgenol. 2007;188:W274-5

1. Serviço de Imagiologia. Hospital do Divino Espírito Santo de Ponta Delgada. Ponta Delgada. Portugal.

$\bowtie$ Autor correspondente: Sofia Martins Amante. sofia.ma.1990@gmail.com.

Recebido: 05 de dezembro de 2018 - Aceite: 24 de abril de 2019 | Copyright @ Ordem dos Médicos 2020 